\title{
Apyrase treatment of myocardial infarction according to a clinically applicable protocol fails to reduce myocardial injury in a porcine model
}

\author{
Jesper van der Pals', Sasha Koul ${ }^{1}$, Michael I Götberg ${ }^{1}$, Göran K Olivecrona' ${ }^{1}$, Martin Ugander ${ }^{2}$, Mikael Kanski ${ }^{2}$, \\ Andreas Otto ${ }^{2}$, Matthias Götberg ${ }^{1}$, Håkan Arheden², David Erlinge ${ }^{1 *}$
}

\begin{abstract}
Background: Ectonucleotidase dependent adenosine generation has been implicated in preconditioning related cardioprotection against ischemia-reperfusion injury, and treatment with a soluble ectonucleotidase has been shown to reduce myocardial infarct size (IS) when applied prior to induction of ischemia. However, ectonucleotidase treatment according to a clinically applicable protocol, with administration only after induction of ischemia, has not previously been evaluated. We therefore investigated if treatment with the ectonucleotidase apyrase, according to a clinically applicable protocol, would reduce IS and microvascular obstruction (MO) in a large animal model.
\end{abstract}

Methods: A percutaneous coronary intervention balloon was inflated in the left anterior descending artery for 40 min, in 16 anesthetized pigs (40-50 kg). The pigs were randomized to $40 \mathrm{~min}$ of $1 \mathrm{ml} / \mathrm{min}$ intracoronary infusion of apyrase $(10 \mathrm{U} / \mathrm{ml}, \mathrm{n}=8)$ or saline $(0.9 \mathrm{mg} / \mathrm{ml}, \mathrm{n}=8)$, twenty minutes after balloon inflation. Area at risk (AAR) was evaluated by ex vivo SPECT. IS and MO were evaluated by ex vivo MRI.

Results: No differences were observed between the apyrase group and saline group with respect to IS/AAR (75.7 $\pm 4.2 \%$ vs $69.4 \pm 5.0 \%, \mathrm{p}=\mathrm{NS})$ or $\mathrm{MO}(10.7 \pm 4.8 \%$ vs $11.4 \pm 4.8 \%, \mathrm{p}=\mathrm{NS})$, but apyrase prolonged the postischemic reactive hyperemia.

Conclusion: Apyrase treatment according to a clinically applicable protocol, with administration of apyrase after induction of ischemia, does not reduce myocardial infarct size or microvascular obstruction.

\section{Background}

Despite great advances in the treatment of ischemic heart disease, acute myocardial infarction remains the most common cause of death in the western world [1]. Modern therapy of acute myocardial infarction is aimed at reperfusion of the ischemic tissue in order to reduce myocardial infarct size (IS) and the extent of complications [2-6]. Although the final infarct size is reduced by early reperfusion, reperfusion per se may lead to immediate and accelerated injury beyond that which is generated by ischemia alone, a phenomenon referred to as "reperfusion injury" $[7,8]$. Myocardial ischemia may also damage the endothelium leading to impairment of the microvascular blood flow (microvascular

\footnotetext{
* Correspondence: david.erlinge@med.lu.se

${ }^{1}$ Department of Cardiology, Lund University Hospital, Lund, Sweden
}

obstruction, MO). In the clinical setting, MO is common and an independent predictor of poorer clinical outcome [9]. Consequently, there is a need for an adjunctive cardioprotective therapy for myocardial salvage beyond what reperfusion therapy alone can provide.

A theoretical possibility is to utilize the adenosine receptor system, which seems to represent an innate protection system in the heart. Extracellular adenosine is mainly generated from a two-step dephosphorylation from adenosine triphosphate (ATP) by a family of enzymes collectively known as ectonucleotidases. ATP is degraded to adenosine monophosphate (AMP) by CD39, also called apyrase or nucleoside triphosphate diphosphohydrolase. AMP is converted to adenosine by CD73, also called ecto-5'-nucleotidase [10,11], and is 
released by the cells of the cardiovascular system in response to various injurious stimuli or ischemic insult [12]. Although adenosine formation may be important, the formation of adenosine from ATP and AMP is limited due to the availability of CD39 and CD73 which are thus rate-limiting for extracellular adenosine formation [13]. Adenosine activates adenosine receptors on a variety of cells [10], and in the heart it plays a role in regulating, among other things, coronary blood flow, heart rate, cardiac conduction and substrate metabolism [12]. Adenosine is also known to affect several of the proposed reperfusion injury mechanisms, promoting preservation of microvascular flow, reducing reactive oxygen species (ROS) synthesis, stabilising cellular membranes, restoring calcium homeostasis and modifying the inflammatory process [14-22]. ATP, on the contrary, has been found to have cardiotoxic effects [23].

Ectonucleotidase-dependent adenosine generation has also been implicated in pre- and postconditioning related cardioprotection against ischemia-reperfusion injury [24]. The molecular mechanisms involved in preconditioning are not completely understood but are believed to involve adenosine receptor dependent activation of mitochondrial ATP-sensitive $\mathrm{K}+\left(\right.$ mitoK $\left._{\mathrm{ATP}}\right)$ channels and protein kinase C (PKC) [24]. The exact relationship between mitoK $\mathrm{ATP}_{\mathrm{AT}}$ PKC, and the end effectors remains to be clarified. However, there is evidence of cardiomyocyte modulation of sarcoplasmatic reticulum $\mathrm{Ca}^{2+}$ handling, and ATP depletion with secondary effects on the mitochondrial permeability transition pore (MPTP) leading to apoptosis [12,25-29]. Similarly to preconditioning, postconditioning appears to activate signalling pathways that involve adenosine, mitoK $K_{\mathrm{ATP}}$ and PKC, with subsequent effects on MPTPs. In that respect, pre- and postconditioning seem to converge on signalling pathways that involve adenosine and are active primarily during reperfusion [30,31].

Moreover, inhibition of ATP degradation via targeted gene deletion or inhibition of CD39 and CD73 has been found to eliminate the cardioprotective effect of preconditioning [32], and increase infarct size [33]. Ectonucleotidase treatment with apyrase (CD39) has also been shown to reduce myocardial infarct size (IS) when applied prior to induction of ischemia [33].

However, apyrase treatment according to a clinically applicable protocol, with administration only after induction of ischemia, has not previously been evaluated. We therefore investigated if apyrase treatment, administered after induction of ischemia, would reduce IS and MO. Apyrase was chosen because it potentially could confer a double benefit in simultaneously generating cardioprotective adenosine and reducing cardiotoxic ATP [23].

\section{Methods}

\section{Experimental preparation}

16 healthy domestic male and female $40-50 \mathrm{~kg}$ pigs were fasted overnight with free access to water. Premedication was administered with azaperone (Stresnil Vet., Leo; Helsingborg, Sweden), $2 \mathrm{mg} / \mathrm{kg}$ intramuscularly, 30 minutes prior to the procedure. After induction of anesthesia with thiopental (Pentothal, Abbott, Stockholm, Sweden) $5-25 \mathrm{mg} / \mathrm{kg}$, the animals were orally intubated with cuffed endotracheal tubes. Thereafter, a slow infusion of $1.25 \mu \mathrm{l} / \mathrm{ml}$ fentanyl (Fentanyl, Pharmalink AB, Stockholm, Sweden) in buffered glucose (25 $\mathrm{mg} / \mathrm{ml}$ ) was started at a rate of $1.5 \mathrm{ml} / \mathrm{min}$ and adjusted as needed. During balanced anesthesia meprobamat (Mebumal, DAK, Copenhagen, Denmark) and thiopental (Pentothal, Abbott, Stockholm, Sweden), was titrated against animal requirements with small bolus doses. Mechanical ventilation was established with a SiemensElema 900B ventilator in the volume-controlled mode, adjusted in order to obtain normocapnia. Initial settings were: respiratory rate of $15 / \mathrm{min}$, tidal volume of $10 \mathrm{ml} /$ $\mathrm{kg}$ and positive end-expiratory pressure of $5 \mathrm{cmH}_{2} \mathrm{O}$. The animals were ventilated with a mixture of dinitrous oxide $(70 \%)$ and oxygen (30\%). The pigs were continuously monitored with electrocardiogram (ECG) and intraarterial blood pressure. Heparin (200 IU/kg) was given intravenously at the start of the catheterization. An $11 \mathrm{~F}$ introducer sheath (Onset, Cordis Co., Miami, FL, USA) was inserted into the surgically exposed left femoral vein. A $10.7 \mathrm{~F}$ Celsius Control $^{\text {TM }}$ catheter (Innercool Therapies Inc, San Diego, CA, USA) was inserted through the sheath and positioned in the inferior vena cava with the tip of the catheter at the level of the diaphragm. Body temperature was measured with a temperature probe (TYCO Healthcare Norden AB, Solna, Sweden) placed in the distal part of the esophagus. The catheter and the temperature probe were connected to the Celsius Control console and the system was set to maintain a normal pig body temperature of $38.0^{\circ} \mathrm{C}$. A 6 F introducer sheath (Onset, Cordis Co. Miami, FL, USA) was then inserted into the surgically exposed left carotid artery upon which a 6 F JL4 Wiseguide ${ }^{\mathrm{rm}}$ (Boston Scientific Scimed, Maple Grove, MN, USA) was inserted into the left main coronary artery. The catheter was used to place a 0.014-inch PT Choice ${ }^{\mathrm{Tm}}$ guide wire (Boston Scientific Scimed, Maple Grove, MN, USA) into the distal portion of the left anterior descending artery (LAD). A 3.0 × $20 \mathrm{~mm}$ Ranger ${ }^{\mathrm{TM}}$ over-the-wire angioplasty balloon (Boston Scientific Scimed, Maple Grove, MN, USA) was then positioned in the mid portion of the LAD, immediately distal to the first diagonal branch. All radiological procedures were performed in an 
experimental catheterization laboratory (Shimadzu Corp., Kyoto, Japan).

In a separate group of pigs $(n=14)$ the general set-up of the experiment as described above, was established. However, a 0.014-inch, $12 \mathrm{MHz}$ pulsed Doppler flow velocity transducer (Jometrics Flowire, Jomed NV, the Netherlands) was positioned in the mid-portion of the LAD. A 0.014-inch PT choice ${ }^{\text {tw }}$ guidewire (Boston Scientific Scimed, Maple Grove, MN, USA) was thereafter inserted into the distal portion of the LAD. A $3.0 \times 20$ $\mathrm{mm}$ over-the-wire Maverick ${ }^{\mathrm{Tm}}$ angioplasty balloon (Boston Scientific Scimed, Maple Grove, MN, USA) was positioned in the mid portion of the LAD, proximal to the flow velocity transducer but distal to the first diagonal branch, followed by the withdrawal of the PT choice guidewire. Continuous coronary velocity flow profiles were displayed and recorded using the Doppler flow wire connected to a FloMap monitor (Cardiometrics, Mountain View, CA, USA).

\section{Experimental protocol}

Ischemia was induced by inflation of the angioplasty balloon for $40 \mathrm{~min}$. An angiogram was performed after inflation of the balloon and before deflation of the balloon in order to verify total occlusion of the coronary vessel and correct balloon positioning. After deflation of the balloon a subsequent angiogram was performed to verify restoration of blood flow in the previously occluded artery. Twenty minutes after balloon inflation, pigs were randomized to $40 \mathrm{~min}$ of $1 \mathrm{ml} / \mathrm{min}$ intracoronary infusion of the ectonucleotidase apyrase (CD39, MDL number MFCD00130542, EC number 232-569-8, CAS number 9000-95-7, article number A6535, lot number 077K7016, Sigma-Aldrich, Stockholm, Sweden; $10 \mathrm{U} / \mathrm{ml}, \mathrm{n}=8)$ or saline $(0.9 \mathrm{mg} / \mathrm{ml}, \mathrm{n}=8)$. According to the specification of the manufacturer, one unit of apyrase will liberate $1.0 \mu$ mole of inorganic phosphate from ATP or ADP per minute at $\mathrm{pH} 6.5$ at $30^{\circ} \mathrm{C}$. The infusion was made through the over-the-wire balloon, selectively into the ischemic area.

The group of animals with flow transducers was used in order to verify cardiac effects of the infusion of apyrase. The animals in the apyrase group $(n=5)$ received an intracoronary infusion of apyrase as decribed above during a 10 minute period of ischemia, induced by inflation of the balloon, whereafter reactive coronary hyperemia was measured and compared to controls $(n=8)$. Flow was measured as average peak velocity (APV) in $\mathrm{cm} / \mathrm{sec}$. In a closed chest pig model it is not possible to measure vessel diameter and doppler flow simultaneously. However, the diameter of the LAD was measured in separate pigs from both the apyrase- and control group during baseline and during reperfusion at the same angle, and was found not to increase or decrease more than $10 \%$ even during maximum reactive hyperemia. Compensation for this only resulted in very minor changes of the results and was therefore not performed.

\section{Imaging}

Ex vivo imaging of the heart was undertaken according to a previous described protocol [34,35]. The MR and SPECT images were analyzed using freely available software (Segment 1.700, Medviso, Lund, Sweden, http:// segment.heiberg.se) [36].

Infarct size and microvascular obstruction assessed by ex vivo MRI

A gadolinium-based MRI contrast agent (Dotarem, gadoteric acid, Gothia Medical, Billdal, Sweden) was administered intravenously $(0.4 \mathrm{mmol} / \mathrm{kg}) 30$ minutes prior to explantation of the heart. The heart was removed $4 \mathrm{~h}$ after initiation of reperfusion. After removal, the heart was immediately rinsed in cold saline and the ventricles were filled with balloons containing deuterated water. MRI was performed using a $1.5 \mathrm{~T}$ Philips Intera CV MR scanner (Philips, Best, the Netherlands). T1-weighted images (time resolution $=20 \mathrm{~ms}$, echo time $=3.2 \mathrm{~ms}$, flip angle $=70^{\circ}$ and 2 averages) with an isometric resolution of $0.5 \mathrm{~mm}$ covering the entire heart were then acquired using a quadrature head coil. The endocardial and epicardial borders of the left ventricular myocardium were manually delineated in short-axis ex vivo images. The volume of the left ventricular myocardium was calculated as the product of the slice thickness $(\mathrm{cm})$ and the area formed by the delineated borders of the epi- and endocardium. The infarct size was determined as the volume of infarcted myocardium $\left(\mathrm{cm}^{3}\right)$. The infarct volume was calculated as the product of the slice thickness $(\mathrm{cm})$ and the area of hyperenhanced pixels $\left(\mathrm{cm}^{2}\right)$ with a signal intensity above the infarction threshold defined as $>8 \mathrm{SD}$ above the mean intensity of non-affected remote myocardium [37]. Microvascular obstruction was defined as hypointense regions in the core of the infarction which had signal intensity less than the threshold for infarction. These regions were manually included in the infarct volume. The volume of microvascular obstruction $\left(\mathrm{cm}^{3}\right)$ was calculated as the difference between the infarct volume before and after manual inclusion of regions of microvascular obstruction. The size of microvascular obstruction was expressed as percent of the total infarct volume. The infarct size was expressed as percent of left ventricular myocardium as well as percent of the area at risk (IS/AAR) in order to adjust for any difference in AAR between the groups.

\section{Ex vivo assessment of area at risk by SPECT}

Single photon emission computed tomography (SPECT) was used to assess the AAR as percent of left ventricular myocardium. Five hundred MBq of ${ }^{99} \mathrm{~m}$ Tc-tetrofosmin was administered intravenously ten minutes before 
deflation of the angioplasty balloon. Ex vivo imaging was performed with a dual head camera (Skylight, Philips, Best, the Netherlands) at 64 projections (60 s per projection) with a $64 \times 64$ matrix and a zoom factor of 2.19 , yielding a digital resolution of $4.24 \mathrm{X} 4.24 \mathrm{X} 4.24$ $\mathrm{mm}$. Iterative reconstruction using maximum likelihood-expectation maximization (MLEM) was performed with a low-resolution Butterworth filter with a cut-off frequency set to 0.6 of Nyquist and order 5.0. No attenuation or scatter correction was applied. Finally short and long-axis images were reconstructed. The endocardial and epicardial borders of the left ventricle that were manually delineated in the MR images were copied to the co-registered SPECT images. A SPECT defect was defined as a region within the MRI-determined myocardium with counts lower than the $55 \%$ of the maximum counts in the myocardium (Ugander $M$, Soneson H, Heiberg E et al. A novel method for quantifying myocardial perfusion SPECT defect size by co-registration and fusion with MRI - an experimental ex vivo imaging pig heart study. Abstract. Proceedings of the Swedish Heart Association Spring Meeting 2008).

\section{Calculation and statistics}

Calculations and statistics were performed using the GraphPad Prism 4.0 software (GraphPad Software, Inc., La Jolla, CA, USA). Values are presented as mean \pm SEM. Statistical significance was accepted when $P<0.05$ (Mann-Whitney's test).

\section{Ethics}

The study conforms to the Guide for the Care and Use of Laboratory Animals, US National Institute of Health (NIH Publication No. 85-23, revised 1996) and was approved by the Ethics Committee of Lund University, Sweden.

\section{Results}

Heart rate and mean arterial pressure did not differ significantly between the groups throughout the experiment, figure 1 and 2 . IS was $28.9 \pm 3.1 \%$ of the left ventricular mass in the apyrase group and $27.0 \pm 3.8 \%$ of the left ventricular mass in the saline group, $\mathrm{p}=\mathrm{NS}$ (figure 3). AAR was $37.9 \pm 3.1 \%$ of the left ventricular mass in the apyrase group and $37.8 \pm 3.4 \%$ of the left ventricular mass in the saline group, $p=$ NS. No differences were seen between the apyrase group and saline group with respect to IS/AAR (75.7 $\pm 4.2 \%$ vs $69.4 \pm$ $5.0 \%, \mathrm{p}=\mathrm{NS})$ or $\mathrm{MO}(10.7 \pm 4.8 \%$ vs $11.4 \pm 4.8 \%, \mathrm{p}=$ NS), figure 4 and $5 . \mathrm{pH}$ and base excess (BE) did not differ between the groups, table 1 . In the group where coronary blood flow was measured, a pronounced postischemic reactive hyperemia was observed. Infusion of apyrase caused a statistically significant increase in the later part of the hyperemic flow, figure 6 .
Table 1 Arterial blood-gas data

\begin{tabular}{llll}
\hline & Saline & Apyrase & P-value \\
\hline $\mathrm{pH}$ - baseline & $7.50( \pm 0.02)$ & $7.49( \pm 0.03)$ & NS \\
$\mathrm{pH}-15 \mathrm{~min}$ & $7.45( \pm 0.03)$ & $7.44( \pm 0.07)$ & $\mathrm{NS}$ \\
$\mathrm{pH}-45 \mathrm{~min}$ & $7.44( \pm 0.02)$ & $7.42( \pm 0.03)$ & $\mathrm{NS}$ \\
$\mathrm{pH}-75 \mathrm{~min}$ & $7.46( \pm 0.02)$ & $7.43( \pm 0.03)$ & $\mathrm{NS}$ \\
Base excess - baseline & $8.10( \pm 0.52)$ & $8.15( \pm 0.78)$ & $\mathrm{NS}$ \\
Base excess - $15 \mathrm{~min}$ & $5.62( \pm 1.14)$ & $6.80( \pm 1.90)$ & $\mathrm{NS}$ \\
Base excess - 45 min & $5.18( \pm 1.00)$ & $5.18( \pm 1.86)$ & $\mathrm{NS}$ \\
Base excess - 75 min & $5.05( \pm 0.79)$ & $5.05( \pm 1.7)$ & $\mathrm{NS}$ \\
\hline
\end{tabular}

Values are expressed as mean and SEM. pH and base excess were similar between the groups throughout the experiment. The unit for base excess is $\mathrm{mmol} / \mathrm{L}$ and for $\mathrm{pH}-\log _{10}\left\{\mathrm{H}^{+}\right\}$

\section{Discussion}

This study evaluates the cardioprotective effect of apyrase treatment, according to a clinically applicable protocol with administration during and after ischemia. The main findings were that IS/AAR and MO were unaffected by apyrase treatment. However, reactive hyperemia was prolonged by apyrase.

The porcine model was chosen because it more closely resembles the human pathophysiology than the rodent models and also allows for a closed chest model utilising human coronary interventional devices. A percutaneous catheter-based approach allows for induction of ischemia with minimum trauma, operation-induced stress and secondary changes in circulatory physiology. The porcine model also offers the possibility of SPECT and MRI for ischemia and infarct size evaluation. Ex vivo MRI allows for acquisition of high resolution images and objective semiautomatic quantification of myocardial infarction, and correlates closely to histology

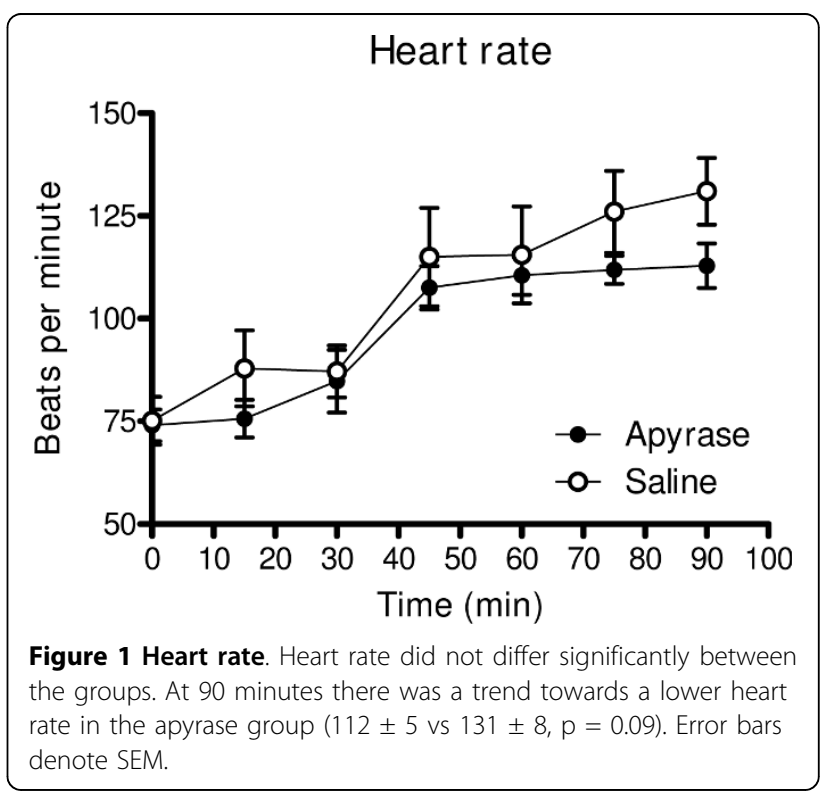




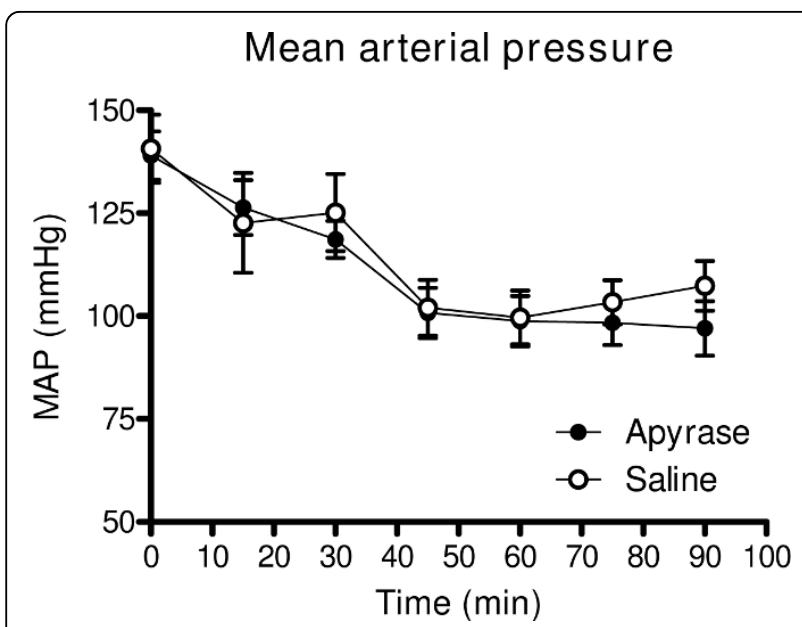

Figure 2 Mean arterial pressure. Mean arterial pressure did not differ significantly between the groups. Error bars denote SEM.

[35,38]. MRI and SPECT are also the gold standard methods of evaluation of ischemia and infarct size in clinical practice. In order to avoid a spontaneous variation in temperature during the experiment, a normal core body temperature of pigs $\left(38^{\circ} \mathrm{C}\right)$ was established before induction of ischemia. A temperature difference between the groups could thus not camouflage a true effect of apyrase treatment. Temperature is known to be a major determinant of infarct size [39]. The placement of the balloon after the first diagonal branch resulted in reproducible ischemia of, on average, $38 \%$ of the left ventricle, with no difference in AAR between the groups.

There was a trend towards lower heart rate in the apyrase group that may be related to the inhibitory effect of generated adenosine on heart rate [40]. However, there were no statistically significant differences in hemodynamic parameters between the groups.

This trial was specifically aimed at evaluating the clinical applicability of apyrase treatment in the setting of ST-segment elevation myocardial infarction (STEMI). The prehospital patient delay time is often significantly longer than the in-hospital door-to-reperfusion time and the window of opportunity for cardioprotective treatment is thus limited to the later part of ischemia [41]. Consequently, apyrase was administered only during the final 20 minutes of ischemia and continued after reperfusion, in order to mimic the clinical situation. The total ischemia time of $40 \mathrm{~min}$ is shorter than in the typical patient with myocardial infarction, which typically experience 2-4 hours of ischemia before start of treatment. However, pigs complete myocardial infarction more rapidly than humans, and longer duration of ischemia have resulted in a large established infarct before initiation of apyrase treatment [42].
Previously, apyrase treatment has been shown to reduce IS/AAR with $43 \%$ when administered 30 minutes prior to a period of 60 minutes of ischemia in a rodent model [33]. In that study, $80 \mathrm{U} / \mathrm{kg}$ of apyrase was administered in wild-type mice. With an average mouse weight of $20 \mathrm{~g}$ and a percentage distribution of cardiac output with $18 \%$ going to the heart during rest [43], $0.28 \mathrm{U}$ of apyrase would have been delivered to the heart. In our study, an approximately 1400 times higher dose of $400 \mathrm{U}$ was infused directly into the ischemic area in order to maximize the possible cardioprotective effect of apyrase treatment at this later timepoint. The finding of prolonged coronary reactive hyperemia induced by apyrase-infusion, suggest that adenosine is generated by the apyrase-infusion. The mechanism behind reactive hyperemia is thought to be multifactorial, but adenosine has been shown to mediate the later phase of hyperemic flow via A2A receptors on smooth muscle cells $[44,45]$. Thus, an increased level of adenosine would be expected to increase the later phase of hyperemia, which it did in our experiment. This observation is also consistent with findings of an accelerated recovery of microvascular circulation after intracoronary infusion of adenosine as an adjunct to primary PCI [46].

The lack of cardioprotective effect of the apyrase-infusion could be explained by species-related differences in the pharmacology of adenosine receptors. It is also possible that apyrase was not able to generate enough adenosine to activate signalling via the $\mathrm{A} 2 \mathrm{~B}$ receptor, which otherwise has been able to yield cardioprotection when stimulated prior to reperfusion by the receptor agonist AMP 579 in a porcine model [47]. Indeed, the A2B receptor is known to be of lower affinity for adenosine than the A2A receptor [48], which seemed to respond with the increased flow seen at the end of reactive hyperemia in the apyrase group $[44,45]$. However, there is also evidence of A2A mediated cardioprotection against ischemia-reperfusion injury [12]. Theoretically, the high dose of apyrase that was used could also have a cardiotoxic effect. However, we are not aware of any such evidence in the literature. The lack of effect could also be explained by a species-related imbalance between apyrase and downstream adenosine generation by CD73 as well as by a low release of native ATP and AMP. A relative deficiency of AMP degradation capacity would be in agreement with the uncertain effect of postconditioning in pigs. Two studies of postconditioning in pig have been carried out where one was negative and the other was negative in one arm with 4 cycles of ischemia/reperfusion and positive in another arm with 8 cycles $[49,50]$. In another study in a porcine model, preconditioning was found to be cardioprotective [51]. In that study, cardiac adenosine levels were measured in the preconditioning group and found to be increased 


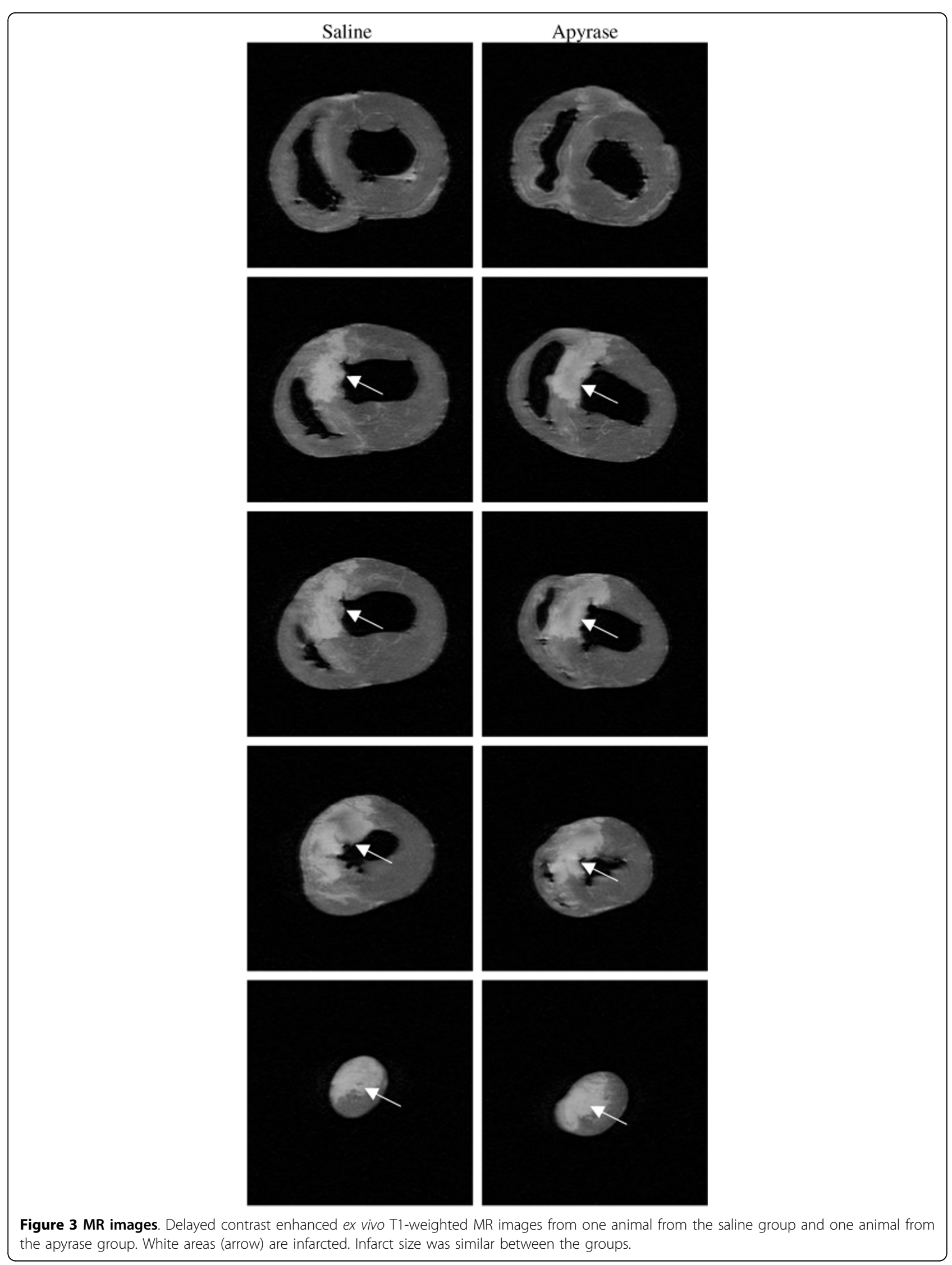




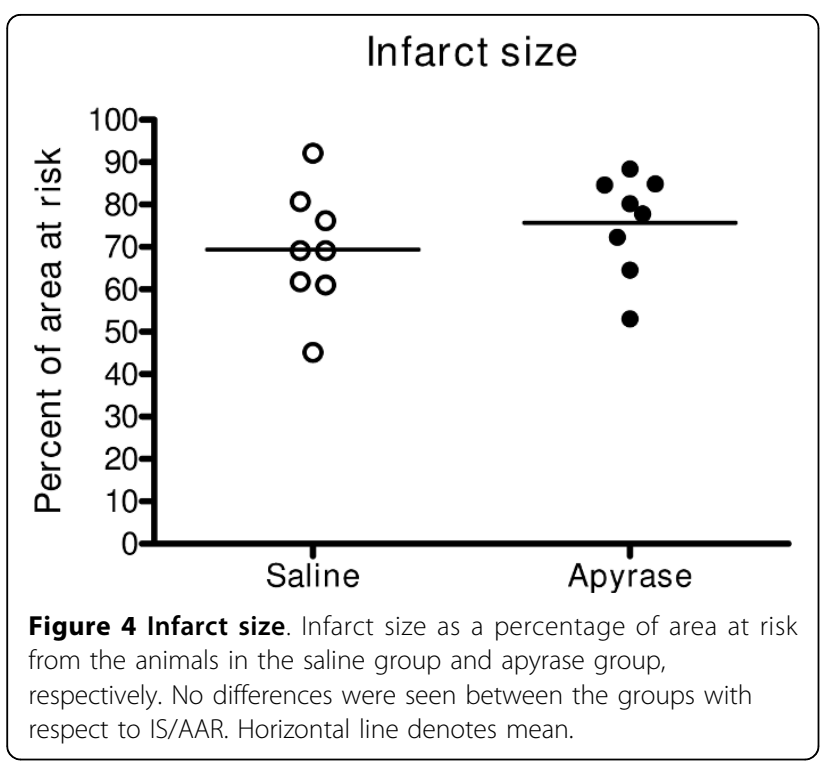

during preconditioning but attenuated during ischemia. In the control group, the adenosine concentration was elevated during ischemia, as opposed to the finding in the preconditioning group [51]. The increased adenosine level during ischemia seen in the control group is in agreement with the experimental protocol in our study. This clearly supports the conclusion that the apyrase infusion must be initiated prior to the induction of ischemia in order to generate a cardioprotective effect. Thus, it is possible that apyrase treatment could prove to be cardioprotective if initiated earlier than in the current study, but it would be of little interest in clinical practice. These findings may also imply that other

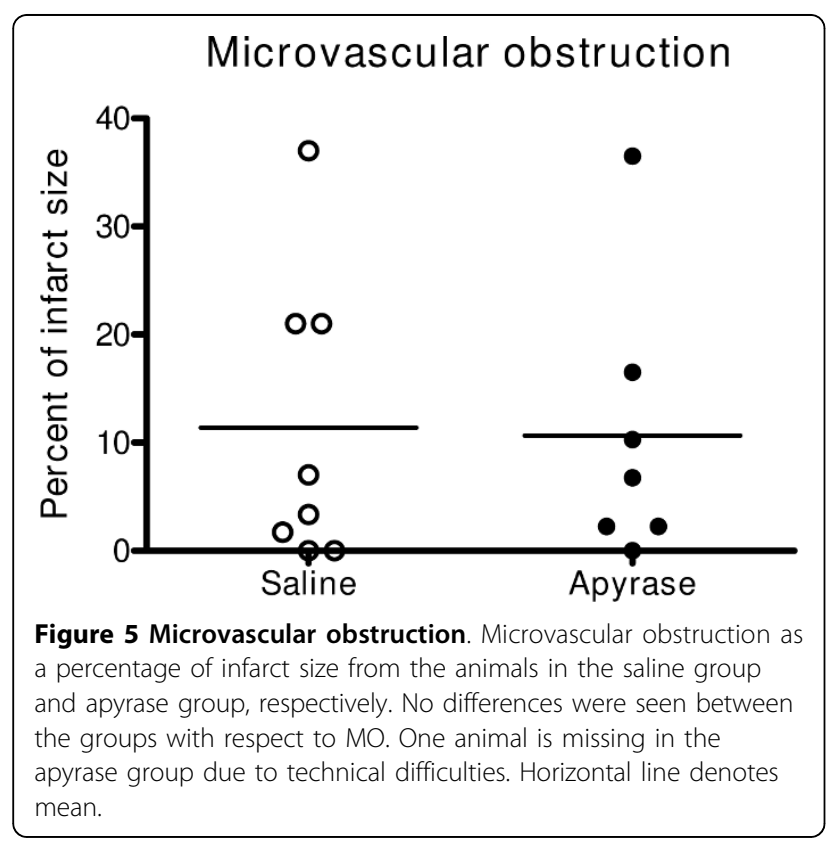

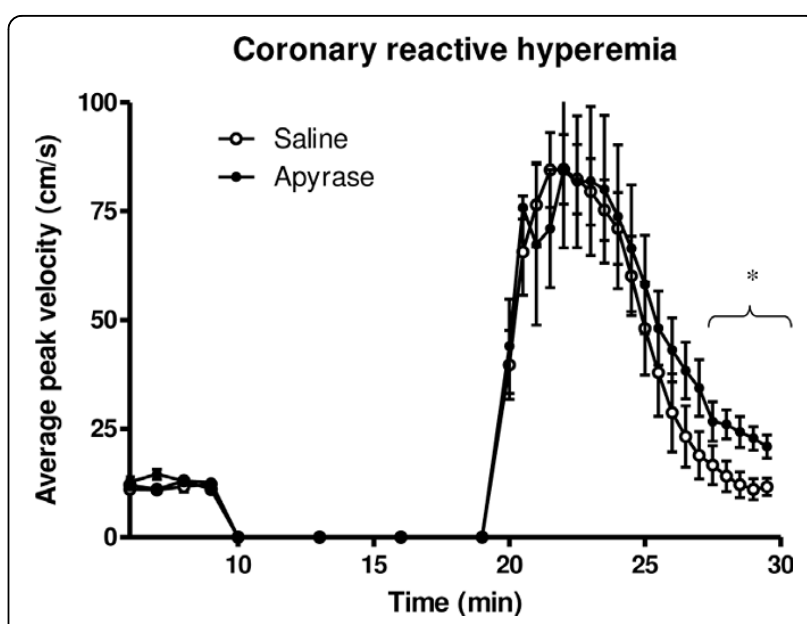

Figure 6 Reactive hyperemia. Post ischemic coronary reactive hyperemia was increased during the later phase by infusion of apyrase ( $p<0.05$, time-points marked by the bracket). Error bars denote SEM.

triggers of pre- and postconditioning, such as bradykinin, opioids, nitric oxide and reactive oxygen species $[30,31,52]$, could be of greater importance than adenosine in the setting of pre- and postconditioning. Furthermore, these factors may explain why apyrase infusion has been found to reduce infarct size in a rodent model but not in our porcine model.

It may be of interest to study whether or not apyrase treatment is cardioprotective in the setting of non-ST elevation acute coronary syndrome, where ischemia may be less sudden in onset and time to coronary intervention longer. In this less sudden setting the stimulatory effect of adenosine on angiogenesis may prove to be effective in tissue protection, in addition to the above mentioned mechanisms of effect [53]. Further research is warranted and the CD39 knockout pig under development may be used to further advance the knowledge in the field.

\section{Limitations}

Histopathological evaluation was not performed. MRI correlates excellent with histological evaluation and this would not affect the outcome parameters. However, histology could have added information about changes at the cellular and molecular levels which could be early indicators of possible beneficial effects of apyrase. Moreover, levels of adenosine and apyrase were not measured, in part because the protocol was maximized regarding intracoronary apyrase administration. A biologically relevant effect of the apyrase infusion was instead confirmed by the finding of an increased reactive hyperemia. However, information about the amount of adenosine that was generated could have conferred additional valuable information. 


\section{Conclusion}

In summary, apyrase treatment according to a clinically applicable protocol, with administration of apyrase only after induction of ischemia, does not reduce myocardial infarct size or microvascular obstruction in the setting of STEMI

\begin{abstract}
Acknowledgements
The study has been supported by the Swedish Scientific Research Council, the Swedish Heart and Lung Foundation, the Vascular Wall program (Lund University Faculty of Medicine), Franke and Margareta Bergqvist Foundation, the Söderberg Foundation and the Zoegas Foundation. We would especially like to thank Holger Eltzschig, MD PhD, for help with developing the initial idea for the study. We would also like to thank Boston Scientific Cardiology, Nordic AB (Helsingborg, Sweden) for their generosity in unrestricted donations of catheters and guide wires for use in animal research and Innercool therapies Inc, San Diego, CA, USA for unrestricted loan of the Celsius Control ${ }^{\mathrm{TM}}$ cooling console.
\end{abstract}

\section{Author details}

'Department of Cardiology, Lund University Hospital, Lund, Sweden.

${ }^{2}$ Department of Clinical Physiology, Lund University Hospital, Lund, Sweden.

\section{Authors' contributions}

The authors have contributed as follows: Conception and design (DE and JVDP), animal experimentation (JVDP, SK, MIG, GO and MG), image design and acquisition (MU, MK, AO and HA), analysis and interpretation (JVDP and $D E$ ), drafting of the manuscript (JVDP and DE), critical revision for important intellectual content (all authors), final approval of the manuscript (all authors)

\section{Competing interests}

The authors declare that they have no competing interests.

Received: 8 October 2009

Accepted: 4 January 2010 Published: 4 January 2010

\section{References}

1. Antman EM, Anbe DT, Armstrong PW, Bates ER, Green LA, Hand M, Hochman JS, Krumholz HM, Kushner FG, Lamas GA, et al: ACC/AHA guidelines for the management of patients with ST-elevation myocardial infarction; A report of the American College of Cardiology/American Heart Association Task Force on Practice Guidelines (Committee to Revise the 1999 Guidelines for the Management of patients with acute myocardial infarction). Journal of the American College of Cardiology 2004, 44(3):E1-E211.

2. Andersen $H R$, Nielsen $T$, Rasmussen $K$, Thuesen $L$, Kelbaek $H$, Thayssen $P$, Abildgaard U, Pedersen F, Madsen JK, Grande P, et al: A comparison of coronary angioplasty with fibrinolytic therapy in acute myocardial infarction. The New England journal of medicine 2003, 349(8):733-742.

3. Kastrati A, Mehilli J, Dirschinger J, Schricke U, Neverve J, Pache J, Martinoff S, Neumann FJ, Nekolla S, Blasini R, et al: Myocardial salvage after coronary stenting plus abciximab versus fibrinolysis plus abciximab in patients with acute myocardial infarction: a randomised trial. Lancet 2002, 359(9310):920-925

4. Keeley EC, Boura JA, Grines CL: Primary angioplasty versus intravenous thrombolytic therapy for acute myocardial infarction: a quantitative review of 23 randomised trials. Lancet 2003, 361(9351):13-20.

5. Fox KA, Dabbous OH, Goldberg RJ, Pieper KS, Eagle KA, Werf Van de F, Avezum A, Goodman SG, Flather MD, Anderson FA Jr, et al: Prediction of risk of death and myocardial infarction in the six months after presentation with acute coronary syndrome: prospective multinational observational study (GRACE). Bmj 2006, 333(7578):1091.

6. Claeys MJ, Bosmans J, Veenstra L, Jorens P, De Raedt H, Vrints CJ. Determinants and prognostic implications of persistent ST-segment elevation after primary angioplasty for acute myocardial infarction: importance of microvascular reperfusion injury on clinical outcome. Circulation 1999, 99(15):1972-1977.
7. Ambrosio G, Tritto II: Lethal Myocardial Reperfusion Injury: Does it Exist, Should We Treat It?. Journal of thrombosis and thrombolysis 1997, 4(1):6970.

8. Kloner RA: Does reperfusion injury exist in humans?. Journal of the American College of Cardiology 1993, 21(2):537-545.

9. Wu KC, Zerhouni EA, Judd RM, Lugo-Olivieri CH, Barouch LA, Schulman SP, Blumenthal RS, Lima JA: Prognostic significance of microvascular obstruction by magnetic resonance imaging in patients with acute myocardial infarction. Circulation 1998, 97(8):765-772.

10. Colgan SP, Eltzschig HK, Eckle T, Thompson LF: Physiological roles for ecto-5'-nucleotidase (CD73). Purinergic Signal 2006, 2(2):351-360.

11. Kaczmarek E, Koziak K, Sevigny J, Siegel JB, Anrather J, Beaudoin AR, Bach FH, Robson SC: Identification and characterization of CD39/vascular ATP diphosphohydrolase. The Journal of biological chemistry 1996, 271(51):33116-33122.

12. Headrick JP, Hack B, Ashton KJ: Acute adenosinergic cardioprotection in ischemic-reperfused hearts. American journal of physiology 2003, 285(5): H1797-1818.

13. Eltzschig HK, Ibla JC, Furuta GT, Leonard MO, Jacobson KA, Enjyoji K, Robson SC, Colgan SP: Coordinated adenine nucleotide phosphohydrolysis and nucleoside signaling in posthypoxic endothelium: role of ectonucleotidases and adenosine $A 2 B$ receptors. The Journal of experimental medicine 2003, 198(5):783-796.

14. Vinten-Johansen J, Thourani VH, Ronson RS, Jordan JE, Zhao ZQ, Nakamura M, Velez D, Guyton RA: Broad-spectrum cardioprotection with adenosine. The Annals of thoracic surgery 1999, 68(5):1942-1948.

15. Zhao ZQ, Budde JM, Morris C, Wang NP, Velez DA, Muraki S, Guyton RA Vinten-Johansen J: Adenosine attenuates reperfusion-induced apoptotic cell death by modulating expression of $\mathrm{Bcl}-2$ and Bax proteins. Journal of molecular and cellular cardiology 2001, 33(1):57-68.

16. Sitkovsky MV: Use of the $\mathrm{A}(2 \mathrm{~A})$ adenosine receptor as a physiological immunosuppressor and to engineer inflammation in vivo. Biochemical pharmacology 2003, 65(4):493-501.

17. Ohta A, Sitkovsky M: Role of G-protein-coupled adenosine receptors in downregulation of inflammation and protection from tissue damage. Nature 2001, 414(6866):916-920.

18. Linden J: Molecular approach to adenosine receptors: receptor-mediated mechanisms of tissue protection. Annual review of pharmacology and toxicology 2001, 41:775-787

19. Deaglio S, Dwyer KM, Gao W, Friedman D, Usheva A, Erat A, Chen JF, Enjyoji K, Linden J, Oukka $M$, et al: Adenosine generation catalyzed by CD39 and CD73 expressed on regulatory T cells mediates immune suppression. The Journal of experimental medicine 2007, 204(6):1257-1265.

20. Yang Z, Day YJ, Toufektsian MC, Ramos SI, Marshall M, Wang XQ, French BA, Linden J: Infarct-sparing effect of A2A-adenosine receptor activation is due primarily to its action on lymphocytes. Circulation 2005, 111(17):2190-2197.

21. Forman MB, Stone GW, Jackson EK: Role of adenosine as adjunctive therapy in acute myocardial infarction. Cardiovascular drug reviews 2006, 24(2):116-147.

22. Monassier JP: Reperfusion injury in acute myocardial infarction: from bench to cath lab. Part II: Clinical issues and therapeutic options. Archives of cardiovascular diseases 2008, 101(9):565-575

23. Mazzola A, Amoruso E, Beltrami E, Lecca D, Ferrario S, Cosentino S, Tremoli E, Ceruti S, Abbracchio MP: Opposite effects of uracil and adenine nucleotides on the survival of murine cardiomyocytes. Journal of cellular and molecular medicine 2008, 12(2):522-536.

24. Peart J, Willems L, Headrick JP: Receptor and non-receptor-dependent mechanisms of cardioprotection with adenosine. American journal of physiology 2003, 284(2):H519-527.

25. Cross HR, Murphy E, Black RG, Auchampach J, Steenbergen C: Overexpression of $A(3)$ adenosine receptors decreases heart rate, preserves energetics, and protects ischemic hearts. American journal of physiology 2002, 283(4):H1562-1568.

26. Headrick JP, Gauthier NS, Berr SS, Morrison RR, Matherne GP: Transgenic A1 adenosine receptor overexpression markedly improves myocardial energy state during ischemia-reperfusion. Journal of molecular and cellular cardiology 1998, 30(5):1059-1064.

27. Zucchi R, Cerniway RJ, Ronca-Testoni S, Morrison RR, Ronca G, Matherne GP Effect of cardiac $A(1)$ adenosine receptor overexpression on 
sarcoplasmic reticulum function. Cardiovascular research 2002, 53(2):326333.

28. Zucchi R, Yu G, Ghelardoni S, Ronca F, Ronca-Testoni S: A3 adenosine receptor stimulation modulates sarcoplasmic reticulum $\mathrm{Ca}(2+)$ release in rat heart. Cardiovascular research 2001, 50(1):56-64.

29. Borutaite $V$, Jekabsone A, Morkuniene R, Brown GC: Inhibition of mitochondrial permeability transition prevents mitochondrial dysfunction, cytochrome $c$ release and apoptosis induced by heart ischemia. Journal of molecular and cellular cardiology 2003, 35(4):357-366.

30. Skyschally A, Schulz R, Heusch G: Pathophysiology of myocardial infarction: protection by ischemic pre- and postconditioning. Herz 2008, 33(2):88-100.

31. Penna C, Mancardi D, Raimondo S, Geuna S, Pagliaro P: The paradigm of postconditioning to protect the heart. Journal of cellular and molecular medicine 2008, 12(2):435-458

32. Eckle T, Krahn T, Grenz A, Kohler D, Mittelbronn M, Ledent C, Jacobson MA, Osswald H, Thompson LF, Unertl K, et al: Cardioprotection by ecto-5'nucleotidase (CD73) and A2B adenosine receptors. Circulation 2007, 115(12):1581-1590

33. Kohler D, Eckle T, Faigle M, Grenz A, Mittelbronn M, Laucher S, Hart ML, Robson SC, Muller CE, Eltzschig HK: CD39/ectonucleoside triphosphate diphosphohydrolase 1 provides myocardial protection during cardiac ischemia/reperfusion injury. Circulation 2007, 116(16):1784-1794.

34. Gotberg M, Olivecrona GK, Engblom H, Ugander M, Pals van der J, Heiberg $E$, Arheden $H$, Erlinge D: Rapid short-duration hypothermia with cold saline and endovascular cooling before reperfusion reduces microvascular obstruction and myocardial infarct size. BMC cardiovascular disorders 2008, 8:7.

35. Kim RJ, Fieno DS, Parrish TB, Harris K, Chen EL, Simonetti O, Bundy J, Finn JP, Klocke FJ, Judd RM: Relationship of MRI delayed contrast enhancement to irreversible injury, infarct age, and contractile function. Circulation 1999, 100(19):1992-2002

36. Heiberg $E$, Engblom $H$, Engvall J, Hedstrom E, Ugander M, Arheden $\mathrm{H}$ : Semi-automatic quantification of myocardial infarction from delayed contrast enhanced magnetic resonance imaging. Scand Cardiovasc J 2005, 39(5):267-275

37. Heiberg E, Ugander M, Engblom H, Gotberg M, Olivecrona GK, Erlinge D, Arheden $\mathrm{H}$ : Automated quantification of myocardial infarction from MR images by accounting for partial volume effects: animal, phantom, and human study. Radiology 2008, 246(2):581-588

38. Wu KC, Kim RJ, Bluemke DA, Rochitte CE, Zerhouni EA, Becker LC, Lima JA: Quantification and time course of microvascular obstruction by contrastenhanced echocardiography and magnetic resonance imaging following acute myocardial infarction and reperfusion. Journal of the American College of Cardiology 1998, 32(6):1756-1764.

39. Schwartz LM, Verbinski SG, Heide Vander RS, Reimer KA: Epicardial temperature is a major predictor of myocardial infarct size in dogs. Journal of molecular and cellular cardiology 1997, 29(6):1577-1583.

40. Dhalla AK, Shryock JC, Shreeniwas R, Belardinelli L: Pharmacology and therapeutic applications of $\mathrm{A} 1$ adenosine receptor ligands. Current topics in medicinal chemistry 2003, 3(4):369-385.

41. Luepker RV, Raczynski JM, Osganian S, Goldberg RJ, Finnegan JR Jr, Hedges JR, Goff DC Jr, Eisenberg MS, Zapka JG, Feldman HA, et al: Effect of a community intervention on patient delay and emergency medical service use in acute coronary heart disease: The Rapid Early Action for Coronary Treatment (REACT) Trial. Jama 2000, 284(1):60-67.

42. Hedstrom E, Engblom H, Frogner F, Astrom-Olsson $\mathrm{K}$, Ohlin $\mathrm{H}$, Jovinge $\mathrm{S}$, Arheden $\mathrm{H}$ : Infarct evolution in man studied in patients with first-time coronary occlusion in comparison to different species - implications for assessment of myocardial salvage. J Cardiovasc Magn Reson 2009, 11(1):38.

43. Gulati OP, Ponard G: Cardiac output and regional blood flow studies in golden hamsters. Experientia 1980, 36(8):984-985.

44. Zatta AJ, Headrick JP: Mediators of coronary reactive hyperaemia in isolated mouse heart. British journal of pharmacology 2005, 144(4):576-587.

45. Saito D, Steinhart CR, Nixon DG, Olsson RA: Intracoronary adenosine deaminase reduces canine myocardial reactive hyperemia. Circulation research 1981, 49(6):1262-1267.

46. Stoel MG, Marques KM, de Cock CC, Bronzwaer JG, von Birgelen C, Zijlstra F: High dose adenosine for suboptimal myocardial reperfusion after primary PCl: A randomized placebo-controlled pilot study. Catheter Cardiovasc Interv 2008, 71(3):283-289.

47. Smits GJ, McVey M, Cox BF, Perrone MH, Clark KL: Cardioprotective effects of the novel adenosine A1/A2 receptor agonist AMP 579 in a porcine model of myocardial infarction. The Journal of pharmacology and experimental therapeutics 1998, 286(2):611-618.

48. Schulte G, Fredholm BB: Signalling from adenosine receptors to mitogenactivated protein kinases. Cellular signalling 2003, 15(9):813-827.

49. Schwartz $L M$, Lagranha $C J$ : Ischemic postconditioning during reperfusion activates Akt and ERK without protecting against lethal myocardial ischemia-reperfusion injury in pigs. American journal of physiology 2006, 290(3):H1011-1018

50. Niodromitis EK, Georgiadis M, Cohen MV, Downey JM, Bofilis E, Kremastinos DT: Protection from post-conditioning depends on the number of short ischemic insults in anesthetized pigs. Basic research in cardiology 2006, 101(6):502-507.

51. Skyschally A, Schulz R, Gres P, Konietzka I, Martin C, Haude M, Erbel R, Heusch G: Coronary microembolization does not induce acute preconditioning against infarction in pigs-the role of adenosine. Cardiovascular research 2004, 63(2):313-322.

52. Iliodromitis EK, Miki T, Liu GS, Downey JM, Cohen MV, Kremastinos DT: The PKC activator PMA preconditions rabbit heart in the presence of adenosine receptor blockade: is $5^{\prime}$-nucleotidase important?. Journal of molecular and cellular cardiology 1998, 30(11):2201-2211.

53. Teuscher $E$, Weidlich V: Adenosine nucleotides, adenosine and adenine as angiogenesis factors. Biomedica biochimica acta 1985, 44(3):493-495.

\section{Pre-publication history}

The pre-publication history for this paper can be accessed here:http://www biomedcentral.com/1471-2261/10/1/prepub

doi:10.1186/1471-2261-10-1

Cite this article as: van der Pals et al:: Apyrase treatment of myocardia infarction according to a clinically applicable protocol fails to reduce myocardial injury in a porcine model. BMC Cardiovascular Disorders 2010 $10: 1$

\section{Publish with Bio Med Central and every scientist can read your work free of charge}

"BioMed Central will be the most significant development for disseminating the results of biomedical research in our lifetime. "

Sir Paul Nurse, Cancer Research UK

Your research papers will be:

- available free of charge to the entire biomedical community

- peer reviewed and published immediately upon acceptance

- cited in PubMed and archived on PubMed Central

- yours - you keep the copyright
BioMedcentral 